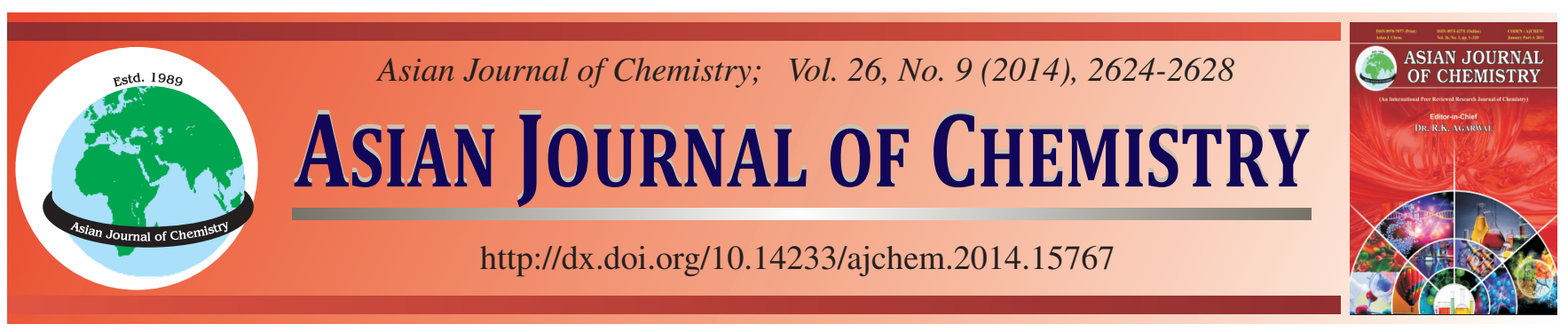

\title{
One-step Extraction and Sensitive Measurement of Polar and Non-Polar Pollutants Simultaneously in Soil Using Modified Ultrasonic Technology with in situ Derivatization
}

\author{
Jianye Gui, Chenling Zhang, Yongtao Zhang, Li Zhang ${ }^{*}$, Jixiang Qi, Xiaoya Li, Laisheng Tai and Guoxing Zhao
}

Institute of Hydrogeology and Environmental Geology, CAGS, Zhengding 050803, P.R. China

*Corresponding author: Fax: +86 311 88017401; Tel: +86 311 88017400; E-mail: agui_mail@163.com

A simple low-cost ultrasonic extraction procedure has been developed for determination of polar aromatic acids, polar phenols and nonpolar pesticides simultaneously in soil. This procedure was accomplished by in situ derivatization as well as elevated temperature, increased power and dispersing intimate contact of solvent with samples. Combined with GC/NCI/MS method, the sensitivity was improved remarkably because of the enhanced electronegativity of derivatized products of herbicide and phenols as well as the intrinsic electronegativity of organochlorine. The method presented here showed that the modified ultrasonic extraction method can be a robust preparation methodology for both polar and nonpolar organic contaminants which can be applied to solid sample pre-treatment extensively.

Keywords: Ultrasonic extraction, Herbicide, Phenols, Organochlorine, Polar, Non-polar, NCI, Soil.

\section{INTRODUCTION}

There is a long-lasting desire for simultaneous determination of polar and non-polar contaminants in soil, but unfortunately many difficulties need to overcome, including both extraction and instrumental determination. It is well known that many polar contaminants such as chlorinated acidic herbicides is not amenable for GC analysis, but many non-polar contaminants such as organochlorine is just suitable for GC analysis. This contradiction was solved by Famiglini et al. ${ }^{1}$, which was based on a special-designed instrument named LC/ direct-EI-MS. Many analytical scientists has developed derivatization method for GC analysis. Polarity of phenols or others can be reduced through esterification ${ }^{2}$, this work has paved the way for simultaneous determination. Likewise, polar and non-polar compounds require different extraction methods. In previous work, we reported the first simultaneous extraction method for polar and non-polar compounds with accelerated solvent extraction (ASE) $)^{3}$. However among the extraction instruments, accelerated solvent extraction is the most expensive one, maybe it is not available in many labs.

Ultrasonic cleaner is a common mini type machine which is available in most labs. In most cases, ultrasonic extraction has long been considered not as rigorous as other extraction methods for soils/solids ${ }^{4}$, especially when it comes to multicomponent analysis in soil. In order to improve the ultrasonic extraction efficiency, many approaches were being undertook by analytical scientists ${ }^{5-7}$. Up to now, there is no example for simultaneous ultrasonic extraction for polar and non-polar organic compounds. in situ derivatization or in-cell derivatization is a great idea which has made much progress in the way to simultaneous analysis of polar and non-polar organic compounds. The conception of in situ derivatization was firstly put forward by Hawthorne et $_{\text {al. }}{ }^{8}$, which is by adding polar substance and derivative reagent into non-polar $\mathrm{CO}_{2}$. Recent years, in situ derivatization was applied to many polar chemicals ${ }^{9-13}$.

The aim of the research was to find a simple way to obtain enough extraction efficiency of polar and non-polar analytes in soil together. To the best of our knowledge, it is the first time that ultrasonic extraction and derivatization was synchronized. It is the first robust ultrasonic extraction method for polar and non-polar compounds all together. With this extraction method, no expensive instruments and multi-step derivatization process are required. All the equipment we utilized in the pretreatment was an ultrasonic cleaner and all we should do is to add specific volume reagent to the soil and then one-step ultrasonic extraction is enough to accomplish the pretreatment. So this methodology can be named accelerated ultrasonic extraction (AUE). Combined with the GC/NCI/MS method we have developed before ${ }^{14-15}$, a perfect multi-targets determination scheme for was demonstrated in this work.

\section{EXPERIMENTAL}

The soil used in this experimental study was collected from North China Plain (Clay) and Gansu Loess Plateau (Loess and sandy soil). The samples were air-dried and ground to 
pass a $1.7 \mathrm{~mm}$ sieve (U.S.10 mesh). The ground samples were stored in capped glass jars.

In preparation of the spiked samples, the known amount of soil (either clay, loess, or sandy soil) which was spiked with known volume of herbicides, phenols and organochlorine standards, was added to a bottle, in order to make it homogenized, a little amount of $\mathrm{CH}_{2} \mathrm{Cl}_{2}$ was necessary to help the standard to disperse into the soil.

The analytical standards of herbicide acids were procured from Dr. Ehrenstorfer. Phenols and organochlorine standards were purchased from chemical service. Acetone, $n$-hexane, toluene were purchased from merk. 2,3,4,5,6-Pentafluorobenzyl bromide $(\mathrm{PFBBr})$ was attained from J\&K Chemical Ltd. Ethylenediaminetetraacetic acid tetrasodium salt ( $\mathrm{Na}_{4}$ EDTA) was purchased from Shijiazhaung Jieke chemical Factory. Potassium Carbonate and quartz sand were purchased from Tianjin Damao Chemical reagent Factory.

Pre-dispersal and pre-chelation: Prior to extraction, a certain amount of quartz sand was added to the spiked soil in a mortar, after mixing, $\mathrm{Na}_{4}$ EDTA (about $5 \%$ ) and pure water (over $20 \%$ ) was added to the mortar and the volume of water was large enough to entirely immerse the soil. Then the samples were evaporated overnight. A general optimized procedure was to weigh $4 \mathrm{~g}$ sample, $2 \mathrm{~g}$ quartz and $0.2 \mathrm{~g} \mathrm{Na} \mathrm{N}_{4}$ EDTA into a mortar, the mixture was homogenized well and $1 \mathrm{~mL}$ pure water was added slowly until slurry was formed, chelate and evaporate the sample for over $12 \mathrm{~h}$ after drying, the sample was re-ground to about 10 mesh.

Ultrasonic one step extraction with in situ derivatization procedure: The procedures of ultrasonic extraction and in situ derivatization were carried out simultaneously in the specific derivatization bottle which was fixed in the ultrasonic cleaner. The derivatization bottle with PTFE stopper was purchased from Bei Jing Xinweier Glass Factory. The ultrasonic cleaner (KQ-700DV) was attained from Kun Shan Ultrasonic Instruments Co., Ltd. The developed operation was as followed. The ultrasonic cleaner was preheated to $65^{\circ} \mathrm{C}$. Prepared sample and $4 \mathrm{~mL}$ acetone were added to derivatizating bottle, after shaking gently, $\mathrm{PFBBr}(30 \%) 200 \mu \mathrm{L}$ and $\mathrm{K}_{2} \mathrm{CO}_{3}(30 \%) 100$ $\mu \mathrm{L}$ were added to the bottle successively. The bottle was then capped and placed in the preheated ultrasonic cleaner, the power wattage was adjusted to over 560 watts. The extraction and derivatization time was $40 \mathrm{~min}$. If necessary, the extract can be purified by clean-up procedure provided by Environmental Protection Agency (EPA) $363{ }^{\circ} \mathrm{C}^{16}$, the supernatant liquor was limpid, the supernatant liquor can be filtrated through the filter $(0.22 \mu \mathrm{m})$ and then be capped in the GC vial directly for analysis.

Instrumentation: The gas chromatographic system consisted of a gas chromatograph GC-2010 equipped with an autosampler AOC 20 is, a split/splitless injector and a mass spectrometer equipped with an negative chemical ion source (NCI), (Shimadzu Corporation). A DB-5MS capillary column (J\&W Scientific) was used, with the dimensions of $30 \mathrm{~m}$ length, $0.25 \mathrm{~mm}$ i.d. and $0.25 \mu \mathrm{m}$ film thickness. The injection port liner used was of a packed single taper type and kept at 230 ${ }^{\circ} \mathrm{C}$. The GC/MS ion source and transfer line temperatures were 200 and $230{ }^{\circ} \mathrm{C}$, respectively. The analysis was conducted in
NCI and selected ion monitoring (SIM) modes using methane (purity $99.999 \%$ ) as a reagent gas. The ion source pressure was set at about $1.0 \mathrm{~Pa}$ and system vaccum pressure was better than $2 \times 10^{-3} \mathrm{~Pa}$. The ions monitored were as Table- 2 for the 2,3,4,5,6-pentafluorobenzyl bromide derivatives of the analytes. The GC oven temperature started from $90^{\circ} \mathrm{C}$ for $1 \mathrm{~min}$ and was ramped at $30^{\circ} \mathrm{C} / \mathrm{min}$ to $200{ }^{\circ} \mathrm{C}$ and then was ramped at $10{ }^{\circ} \mathrm{C} / \mathrm{min}$ to $300{ }^{\circ} \mathrm{C}$ held for $2 \mathrm{~min}$.

\section{RESULTS AND DISCUSSION}

In order to monitoring the recoveries of three types of compounds simultaneously, first of all, a set of GC/NCI/MS method was developed. It is well known that the GC-MS with $\mathrm{NCI}$ is amenable to both the derivatizated polar compounds of $\mathrm{PFBBr}^{14}$ and the organochlorine respectively. To merge the two determination processes is not a difficult problem. After derivatization the polarity of the 3 categories of organic compounds became concordant because of esterification, the high electronegativity of those was obtained because of the introduced element-fluorine, in this case, the whole monitoring process can be integrated into one temperature-programming of GC and one mass spectra acquisition of NCI MS detector. The optimized parameters were listed in Table-1.

Potential of ultrasonic technology: Traditional ultrasonic technology usually served as a rinse or clean-up enhancer. As a extraction method, it often suffered from instability and low recovery, especially for polar organic compounds. As a matter of fact, much potential or many parameters can be implemented to this technology, such as dispersal intimate contact of solvent, boosted power, elevated temperature, derivatization reaction and chelating impetus.

Optimization of ultrasonic extraction parameters: The traditional ultrasonic method failed to make good use of temperature, dispersing agent and derivatization. So in present research, elevated temperature and other possible approaches which have potential to improve the efficiency, have been investigated and evaluated.

In this paper, the extraction temperature as well as the derivatization temperature was investigated from $30-70{ }^{\circ} \mathrm{C}$, the data showed that $65^{\circ} \mathrm{C}$ is suitable for extraction and derivatization. The ultrasonic power was studied in the range of 300700 watts (300 is the recommended temperature 4 of EPA 3550c and 700 is the maximum power of the ultrasonic cleaner). Experiment showed that 560 watts can significantly improve the recovery of extraction as well as the derivatization efficiency. The extraction time as well as the derivatization time was evaluated from 10-50 min. Part of the data was listed in Table-2.

Derivatization reagent $\mathrm{PFBBr}$ and catalyst $\mathrm{K}_{2} \mathrm{CO}_{3}$ was chosen according to Zhang et al. ${ }^{15}$, the volume of $\mathrm{PFBBr}$ was optimized in the range from $50-500 \mu \mathrm{L}$. The quantity of $\mathrm{K}_{2} \mathrm{CO}_{3}$ was investigated from $50-200 \mu \mathrm{L}$. The experiment showed that the maximum recovery was attained by using $200 \mu \mathrm{L}$ of $\mathrm{PFBBr}$ (30\%) and $100 \mu \mathrm{L}$ of $\mathrm{K}_{2} \mathrm{CO}_{3}(30 \%)$.

Dispersing reagent is another factor which is easy to be overlooked. To ensure intimate contact of the sample matrix with the extraction solvent is the fundamental condition, to blend appropriate quartz sand can help the extraction solvent 
TABLE-1

ESTABLISHED MONITORING PARAMETERS OF GC/NCI/MS

\begin{tabular}{ccccc}
\hline Compounds & Retention time $(\mathrm{min})$ & $\begin{array}{c}\text { Molecular weight of } \\
\text { derivatized compound }\end{array}$ & Quantitative ion $(\mathrm{m} / z)$ & Reference ion $(\mathrm{m} / z)$ \\
\hline$\alpha$-BHC & 4.73 & - & 71 & 35,73 \\
$\beta$-BHC & 4.97 & - & 35 & 71,73 \\
$\gamma$-BHC & 5.07 & - & 35 & 71,73 \\
$\delta$-BHC & 5.37 & - & 71 & 35,73 \\
2,4,6-Trichlorophenol & 5.52 & 376 & 197 & 195 \\
3,5-Dichlorobenzoic & 5.98 & 370 & 189 & $191,193,190$ \\
MCPP & 6.06 & 394 & 213 & $215,214,216$ \\
Dicamba & 6.65 & 384 & 203 & $205,159,161$ \\
MCPA & 6.76 & 400 & 219 & $221,175,177$ \\
2,3,4,6-Tetrachlorophenol & 6.79 & 412 & 231 & 229,233 \\
Dichloroprop & 6.85 & 380 & 199 & $201,200,202$ \\
2,4-D & 7.29 & 414 & 233 & $235,237,234$ \\
$p, p$-DDE & 7.70 & - & 35 & 37 \\
$2,4,5$-TP & 7.82 & 400 & 219 & $221,223,220$ \\
Pentachlorophenol & 7.90 & 448 & 267 & $269,271,270$ \\
2,4,5-T & 8.32 & 420 & 239 & $240,241,242$ \\
$p, p$-DDD & 8.37 & - & 35 & 37 \\
$p, p$-DDT & 8.98 & - & 35 & 37 \\
$2,4-$ DB & 9.06 & 428 & 247 & $249,161,167$ \\
\hline
\end{tabular}

TABLE-2

RECOVERIES WITH DIFFERENT ULTRASONIC AND EXTRACTION TIME AND DIFFERENT POWER

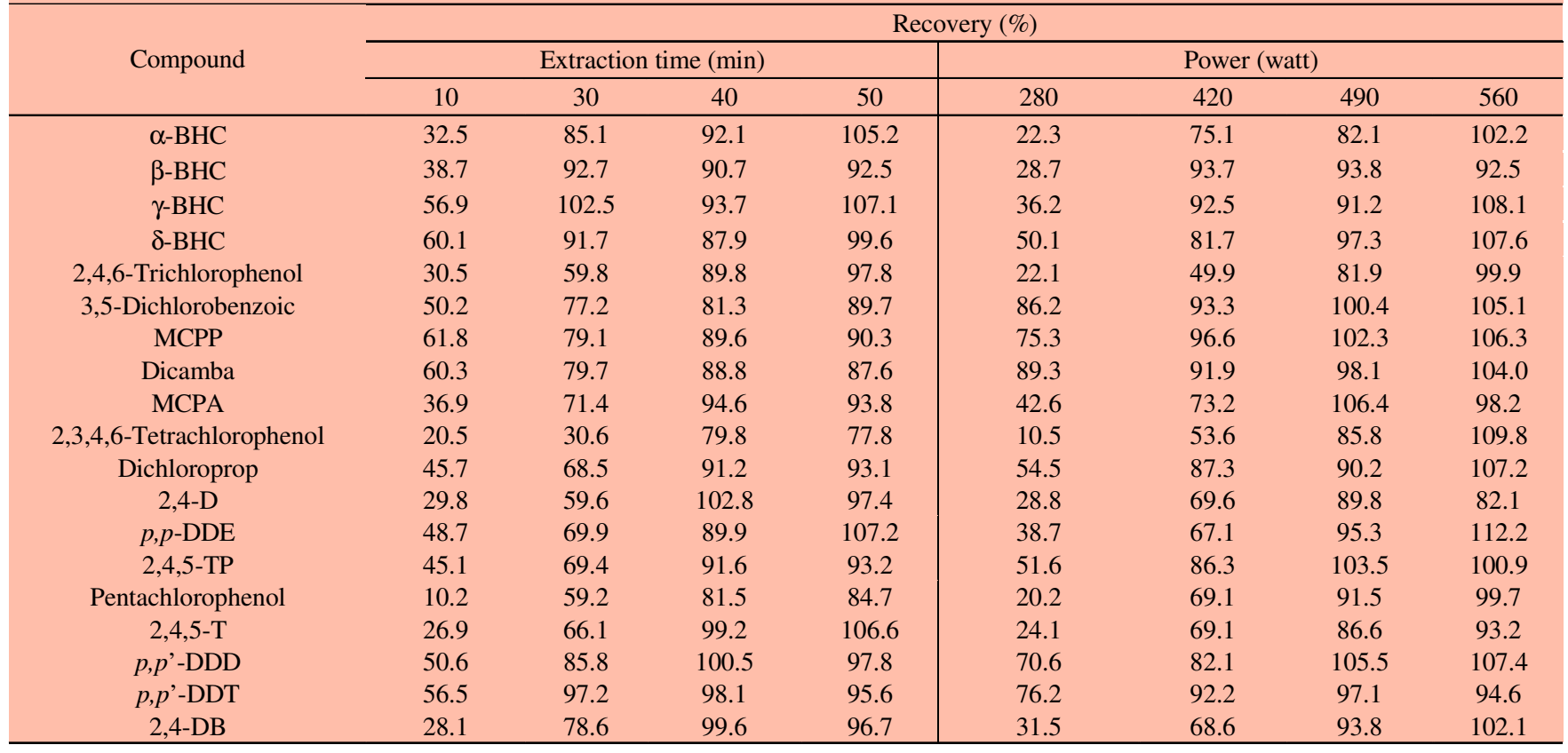

and derivatization reagent to further intimate contact with the analytes in the sample especially for some complex soil.

Roles of $\mathrm{Na}_{4}$ EDTA and quartz sand: In this paper, the special function of $\mathrm{Na}_{4}$ EDTA was discovered that not only does the $\mathrm{Na}_{4}$ EDTA play the role of complexation or chelation ${ }^{15}$, but also it help to precipitate the particulate matter and purify the extract. To some extent, $\mathrm{Na}_{4}$ EDTA played the role of flocculating reagent and dispersed quartz sand played the role of condensation nucleus. In order to extract clearer liquid, $\mathrm{NaCl}, \mathrm{Na}_{2} \mathrm{SO}_{4}, \mathrm{Na}_{4} \mathrm{EDTA}$, quartz sand was added separately and conjunctly. The appearance of extract showed that addition of $\mathrm{Na}_{4}$ EDTA and quartz sand can help clean the extract significantly, for most of the soil sample, after simple filtering with $0.22 \mu \mathrm{m}$ organic filter (Tian Jin Autoscience Corporation), extract can be injected into the GC-MS directly. If without the addition of them, the extracted liquid was just translucent even dark and muddy, in this case, cleanup procedure must be carried out. The theory of this phenomena can been explained as precipitation or flocculation.

Evaluation of main method parameters: Method quality parameters were evaluated according the following operation. 6 g quartz sand samples were spiked with herbicides, phenols and organochlorine standard in the range from 2.5 to $200 \mu \mathrm{g} /$ $\mathrm{kg}$, the procedure of AUE and determination was the same as that of real samples. Correlation coefficient was calculated according to the response intensity of NCI mass detector respectively, 


\begin{tabular}{|c|c|c|c|}
\hline \multicolumn{4}{|c|}{$\begin{array}{c}\text { TABLE-3 } \\
\text { MAIN QUALITATIVE PARAMETER OF THE DERIVATIZATION PRODUCT, CORRELATION COEFFICIENT AND LODs }\end{array}$} \\
\hline Compound & Linear range $(\mu \mathrm{g} / \mathrm{kg})$ & Correlation coefficient $\left(\mathrm{r}^{2}\right)$ & LODs $(\mu \mathrm{g} / \mathrm{kg})$ \\
\hline$\alpha-\mathrm{BHC}$ & $2.5-200.0$ & 0.997 & 0.25 \\
\hline$\beta-\mathrm{BHC}$ & $2.5-200.0$ & 0.996 & 0.33 \\
\hline$\gamma$-BHC & $2.5-200.0$ & 0.997 & 0.29 \\
\hline$\delta$-BHC & $2.5-200.0$ & 0.995 & 0.21 \\
\hline 2,4,6-Trichlorophenol & $2.5-200.0$ & 0.993 & 0.69 \\
\hline 3,5-Dichlorobenzoicoic & $2.5-200.0$ & 0.993 & 0.05 \\
\hline МCPP & $2.5-200.0$ & 0.996 & 0.19 \\
\hline Dicamba & $2.5-200.0$ & 0.994 & 0.19 \\
\hline MCPA & $2.5-200.0$ & 0.999 & 0.09 \\
\hline 2,3,4,6-Tetrachlorophenol & $2.5-200.0$ & 0.989 & 0.61 \\
\hline Dichloroprop & $2.5-200.0$ & 0.999 & 0.25 \\
\hline $2,4-\mathrm{D}$ & $2.5-200.0$ & 0.995 & 0.18 \\
\hline$p, p$-DDE & $2.5-200.0$ & 0.998 & 0.65 \\
\hline $2,4,5-\mathrm{TP}$ & $2.5-200.0$ & 0.998 & 0.08 \\
\hline Pentachlorophenol & $2.5-200.0$ & 0.991 & 0.79 \\
\hline $2,4,5-\mathrm{T}$ & $2.5-200.0$ & 0.992 & 0.13 \\
\hline$p, p$-DDD & $2.5-200.0$ & 0.997 & 0.51 \\
\hline$p, p$-DDT & $2.5-200.0$ & 0.996 & 0.58 \\
\hline 2,4-DB & $2.5-200.0$ & 0.998 & 0.47 \\
\hline
\end{tabular}

\begin{tabular}{|c|c|c|c|c|c|c|}
\hline \multirow[b]{3}{*}{ Compound } & \multicolumn{6}{|c|}{$\begin{array}{c}\text { TABLE-4 } \\
\text { RECOVERIES OF DIFFERENT MATRIX WITH DIFFERENT CONCENTRATION }\end{array}$} \\
\hline & \multicolumn{2}{|c|}{ Loess } & \multicolumn{2}{|c|}{ Sandy soil } & \multicolumn{2}{|c|}{ Clay } \\
\hline & $\begin{array}{l}\text { Average recovery } \\
\qquad(\%, \mathrm{n}=7)\end{array}$ & $\operatorname{RSD}(\%)$ & $\begin{array}{l}\text { Average recovery } \\
\qquad(\%, \mathrm{n}=7)\end{array}$ & RSD (\%) & $\begin{array}{l}\text { Average recovery } \\
\qquad(\%, \mathrm{n}=7)\end{array}$ & $\operatorname{RSD}(\%)$ \\
\hline$\alpha-\mathrm{BHC}$ & 82.1 & 3.5 & 85.6 & 2.9 & 80.9 & 3.2 \\
\hline$\beta-\mathrm{BHC}$ & 82.5 & 5.3 & 97.3 & 1.5 & 78.5 & 2.8 \\
\hline$\gamma$-BHC & 73.9 & 3.2 & 94.7 & 2.7 & 78.3 & 3.9 \\
\hline$\delta$-BHC & 82.1 & 1.7 & 100.8 & 1.9 & 87.5 & 3.2 \\
\hline 2,4,6-Trichlorophenol & 93.8 & 8.2 & 85.4 & 6.1 & 75.6 & 7.4 \\
\hline 3,5-Dichlorobenzoic & 80.5 & 5.2 & 103.9 & 5.7 & 73.2 & 5.8 \\
\hline MCPP & 87.6 & 5.8 & 95.8 & 4.2 & 69.9 & 4.8 \\
\hline Dicamba & 81.6 & 6.1 & 101.6 & 2.8 & 75.5 & 6.9 \\
\hline MCPA & 93.6 & 6.3 & 109.9 & 3.7 & 67.2 & 3.3 \\
\hline 2,3,4,6-Tetrachlorophenol & 75.3 & 7.1 & 89.3 & 5.0 & 76.4 & 6.3 \\
\hline Dichloroprop & 81.2 & 5.5 & 93.7 & 4.3 & 85.3 & 5.6 \\
\hline $2,4-\mathrm{D}$ & 92.8 & 6.3 & 93.3 & 5.6 & 75.4 & 6.1 \\
\hline$p, p-\mathrm{DDE}$ & 79.9 & 3.8 & 98.8 & 1.7 & 79.7 & 3.7 \\
\hline $2,4,5-\mathrm{TP}$ & 90.6 & 8.1 & 107.0 & 4.2 & 85.2 & 4.6 \\
\hline Pentachlorophenol & 71.5 & 7.3 & 95.1 & 5.2 & 76.1 & 6.5 \\
\hline $2,4,5-\mathrm{T}$ & 91.2 & 5.7 & 90.1 & 3.2 & 87.9 & 5.6 \\
\hline$p, p^{\prime}-\mathrm{DDD}$ & 103.2 & 3.6 & 109.0 & 1.5 & 81.6 & 4.8 \\
\hline$p, p^{\prime}-\mathrm{DDT}$ & 92.1 & 2.1 & 100.6 & 3.4 & 93.8 & 4.7 \\
\hline 2,4-DB & 95.7 & 6.6 & 97.3 & 3.1 & 74.4 & 7.5 \\
\hline
\end{tabular}

$\mathrm{r}^{2}$ ranged from 0.989 to $0.999 .4 \mathrm{~g}$ real sample was spiked with $2.5 \mu \mathrm{g} / \mathrm{kg}$ standard, the limits of detection (LODs) were calculated as the compound concentration giving a signal-tonoise ratio of $3(\mathrm{~S} / \mathrm{N}=3)$, Values ranged from 0.05 to $0.79 \mu \mathrm{g} /$ $\mathrm{kg}$. The overall result of the evaluation as well as the main qualitative parameters can be seen in Table-3.

Application to real samples: Recovery studies were carried out by applying the optimized AUE method to the extraction of a series of different matrix real sample spiked at $25 \mu \mathrm{g} / \mathrm{kg}$ and these initial concentration were taken into account to calculate the recoveries. As can be seen in Table-4, the recoveries were between 67.2 and $109.9 \%$ in all cases. The precision was also evaluated and the relative standard deviation (RSD) values were lower than $8.2 \%$.
Comparison between different extraction methods with contaminated soils: The method was validated with real contaminated soils from a farmland. In order to further identify the compounds, both the newly-established AUE and existing accelerated solvent extraction (ASE) method ${ }^{15}$ was used as a comparison. Results are consistent with each other approximately. Furthermore, the contaminated soils with spiked standards was extracted and detected, the result was showed in Table-5.

\section{Conclusion}

We have developed a prototype for simultaneous one-step extraction of different polar compounds which was based on a novel extraction approach, named as accelerated ultrasonic 


\begin{tabular}{|c|c|c|c|c|c|c|}
\hline \multirow{3}{*}{ Compound } & \multicolumn{6}{|c|}{$\begin{array}{l}\text { TABLE-5 } \\
\text { ITH DIFFERENT EXTRACTION METHODS AND THEIR } \\
\text { RESULTS WITH SPIKED STANDARDS }\end{array}$} \\
\hline & \multicolumn{2}{|c|}{ Result of sample-1 $(\mu \mathrm{g} / \mathrm{kg})$} & \multicolumn{2}{|c|}{$\begin{array}{c}\text { Result of sample-2 result of } \\
\text { sample- } 1(\mu \mathrm{g} / \mathrm{kg})\end{array}$} & \multicolumn{2}{|c|}{ Samples spiked with $50.0(\mu \mathrm{g} / \mathrm{kg})$} \\
\hline & With AUE & With ASE & With AUE & With ASE & Sample-1 AUE & Sample-2 AUE \\
\hline$\alpha-\mathrm{BHC}$ & - & - & - & - & 42.3 & 46.4 \\
\hline$\gamma-\mathrm{BHC}$ & - & - & - & - & 46.2 & 53.4 \\
\hline$\delta-\mathrm{BHC}$ & - & - & & & 37.9 & 39.4 \\
\hline 2,4,6-Trichlorophenol & 11.1 & 13.6 & - & - & 59.9 & 54.2 \\
\hline 3,5-Dichlorobenzoic & & & - & - & 45.9 & 44.7 \\
\hline MCPP & - & - & - & - & 48.9 & 50.3 \\
\hline Dicamba & & & & & 45.4 & 44.4 \\
\hline MCPA & & & 14.2 & 16.7 & 48.2 & 69.8 \\
\hline Dichloroprop & & & & & 47.9 & 45.8 \\
\hline $2,4-\mathrm{D}$ & 70.2 & 76.1 & & & 118.1 & 51.6 \\
\hline$p, p-\mathrm{DDE}$ & & & & & 48.1 & 46.3 \\
\hline $2,4,5-\mathrm{TP}$ & & & & & 47 & 49.9 \\
\hline Pentachlorophenol & & & & & 46.5 & 42.8 \\
\hline $2,4,5-\mathrm{T}$ & & & & & 49.3 & 49.3 \\
\hline$p, p$ '-DDD & & & & & 48.6 & 49.0 \\
\hline$p, p$ '-DDT & & & & & 42.7 & 46.1 \\
\hline 2,4-DB & & & & & 46.7 & 42.2 \\
\hline
\end{tabular}

extraction (AUE). Quantitatively recoveries can be attained with the elevated temperature, enhanced power, additional dispersal and chelation. Combined with developed GC-NCIMS method, a satisfied recoveries, precisions and LODs were achieved, the reliability of the method was demonstrated through a broad range of soil samples.

It is a rapid procedure that all samples pretreatment can take place in the little specific derivatization bottle which was fixed in the ultrasonic cleaner. Since dozens of derivatization bottles can be fixed in the ultrasonic cleaner all together, so the procedures for extraction and derivatization of dozens of samples can be accomplished simultaneously in less than $1 \mathrm{~h}$. To our best of knowledge, it was the first simplest method which integrated extraction and derivatization together with the most common ultrasonic technology. This pioneering undertaking has made it possible that the simultaneous determination of polar and non-polar organic pollutants can be achieved in each lab.

\section{ACKNOWLEDGEMENTS}

This research was supported by the project of research on experimental technology and analytical methods of organic containments, China geological survey(Grant No. G201120) and the National Natural Science Foundation of China (Grant No. 41102151). Thanks are also due to Prof. Qi Jixiang for his helpful discussion and much effort at the beginning of the project.

\section{REFERENCES}

1. G. Famiglini, P. Palma, V. Termopoli, H. Trufelli and A. Cappiello, Anal. Chem., 81, 7373 (2009).

2. R.S. Zhao, C.G. Cheng, J.P. Yuan, T. Jiang, X. Wang and J.M. Lin, Anal. Bioanal. Chem., 387, 687 (2007).

3. G. Jianye, W. Fuxiang, Q. Jixiang, C. Zongyu, Z.Z. Ji, Z. Li and Y.T. Zhang, Chin. J. Anal. Chem., 12, 1877 (2011).

4. EPA method $355^{\circ} \mathrm{C}$, Ultrasonic Extraction, Revision 3, November 2000.

5. P.A. Blackwell, H.C. Holten Lützhøft, H.P. Ma, B. Halling-Sørensen and A.B. Boxall, Talanta, 64, 1058 (2004).

6. E. Rodriguez-Gonzalo, R. Carabias-Martinez, E.M. Cruz, J. DominguezAlvarez and J. Hernández-Méndez, J. Sep. Sci., 32, 575 (2009).

7. C. Druart, O. Delhomme, A. Vaufleury, E. Ntcho and M. Millet, Anal. Bioanal. Chem., 399, 1725 (2011).

8. S.B. Hawthorne, D.J. Miller, D.E. Nivens and D.C. White, Anal. Chem., 64, 405 (1992).

9. L. Sanchez-Prado, J.P. Lamas, M. Lores, C. Garcia-Jares and M. Llompart, Anal. Chem., 82, 9384 (2010).

10. T. Zimmermann, W.J. Ensinger and T.C. Schmidt, Anal. Chem., 76, 1028 (2004).

11. M.D. David, S. Campbell and Q.X. Li, Anal. Chem., 72, 3665 (2000).

12. S. Campbell and Q.X. Li, Anal. Chim. Acta, 434, 283 (2001).

13. N. Saim, M. Mohammad, R.D. Hamid and R. Osman, The Malaysian J. Anal. Sci., 12, 500 (2008).

14. J. Gui, L. Zhang, J. Qi, Y. Zhang, H. Zuo, L. Zhang and G. Li, Chin. J. Anal. Chem., 8, 1177 (2010).

15. L. Zhang, J. Gui, J. Qi, Z. Chen, X. Li, Y. Zhang, H. Zuo, F. Wei and H. Wei, Chin. J. Anal. Chem., 8, 1238 (2011).

16. EPA method $363^{\circ} \mathrm{C}$, Silica Gel Cleanup, Revision 3, December 1996. 